\title{
Extensive longitudinal immune profiling reveals sustained innate immune activation in COVID-19 patients with unfavorable outcome
}

\author{
Benjamin Schrijver $^{1, a}$, Jorn L.J.C. Assmann ${ }^{1, a}$, Adriaan J. van Gammeren ${ }^{2}$, \\ Roel C.H. Vermeulen ${ }^{3}$, Lützen Portengen ${ }^{3}$, Peter Heukels ${ }^{4}$, Anton W. Langerak ${ }^{1}$, \\ Willem A. Dik ${ }^{1}$, Vincent H.J. van der Velden ${ }^{1, b}$, Ton A.A.M. Ermens ${ }^{2, b}$ \\ ${ }^{1}$ Department of Immunology, Laboratory Medical Immunology, Erasmus MC-University Medical Center Rotterdam, the Netherlands
2 Department of Clinical Chemistry and Hematology, Amphia Hospital, Breda, the Netherlands
${ }^{3}$ Department of Population Health Sciences, Institute for Risk Assessment Sciences, University Utrecht, Utrecht, the Netherlands
${ }^{4}$ Department of Pulmonology, Amphia Hospital, Breda, the Netherlands
}

Correspondence: Vincent H.J. van der Velden; Department of Immunology, Laboratory Medical Immunology, Erasmus MC, University Medical Center Rotterdam; PO Box 2040, 3000 CA, Rotterdam, the Netherlands

${ }^{\mathrm{a}}$ Shared first author ${ }^{\mathrm{b}}$ Shared last author

Accepted for publication October 16, 2020

To cite this article: Schrijver B, Assmann JLJC, van Gammeren AJ, Vermeulen RCH, Portengen L, Heukels P, Langerak AW, Dik WA, van der Velden VHJ, Ermens TAAM. Extensive longitudinal immune profiling reveals sustained innate immune activation in COVID-19 patients with unfavorable outcome. Eur. Cytokine Netw. 2020; 31(4): 154-167. doi: 10.1684/ecn.2020.0456

\begin{abstract}
COVID-19 differs substantially between individuals, ranging from mild to severe or even fatal. Heterogeneity in the immune response against SARS-COV-2 likely contributes to this. Therefore, we explored the temporal dynamics of key cellular and soluble mediators of innate and adaptive immune activation in relation to COVID-19 severity and progression.

Forty-four patients with a PCR-proven diagnosis of COVID-19 were included. Extensive cellular (leukocytes and T-lymphocyte subsets) and serological immune profiling (cytokines, soluble cell surface molecules, and SARS-CoV-2 antibodies) was performed at hospital admission and every 3-4 days during hospitalization. Measurements and disease outcome were compared between patients with an unfavorable (IC admission and/or death) and favorable (all others) outcome.

Patients with an unfavorable outcome had higher leukocyte numbers at baseline, mostly due to increased neutrophils, whereas lymphocyte and monocyte numbers were reduced. CRP, IL-6, CCL2, CXCL10, and GM-CSF levels were higher at baseline in the unfavorable group, whereas IL-7 levels were lower. SARS-CoV-2 antibodies were more frequently absent in the unfavorable group. Longitudinal analysis revealed delayed kinetics of activated CD4 and CD8 T-lymphocyte subsets in the unfavorable group. Furthermore, whereas CRP, IL-6, CXCL10, and GM-CSF declined in the favorable group, these cytokines declined with delayed kinetics, remained increased, or even increased further in the unfavorable group.

Our data indicate a state of increased innate immune activation in COVID19-patients with an unfavorable outcome at hospital admission, which remained over time, as compared with patients with a favorable outcome.
\end{abstract}

Key words: COVID-19, SARS-CoV-2

\section{INTRODUCTION}

Currently, the world is suffering from a viral pandemic caused by severe acute respiratory syndrome corona virus 2 (SARS-CoV-2) which causes coronavirus disease 2019 (COVID-19). Upon early infection classical non-life-threatening respiratory infectious symptoms among which couch, fever, nasal congestion, and fatigue are observed [1]. A subset of hospitalized patients $(\sim 20 \%)$ does, however, progress to severe or life-threatening disease [2]. This is associated with pneumonia, severe acute respiratory failure, and multiple organ dysfunction, which are postulated to originate from primary or secondary uncontrolled viremia and/or profound immunopathology, with an estimated mortality rate of $\sim 3-5 \%[1,3-5]$.
Host risk factors for severe/fatal COVID-19 have been identified and comprise age, especially above 60 years old, obesity, body mass index (BMI), and related comorbidities (e.g. hypertension, type-2 diabetes) [6-8], although it can be anticipated that numerous genetic factors contribute as well.

SARS-CoV-2 viral transmission occurs through expelled virus-containing aerosols or indirectly by contact with contaminated surfaces. Adherence and infiltration of human cells is achieved through viral spike (S)-protein priming and subsequent binding to the angiotensin-converting enzyme 2 (ACE2) receptor, expressed on pneumocytes and macrophages $[9,11]$ Appropriately initiated and controlled innate and adaptive immune responses are crucial for succesful cleareance of acute viral infection. The diverse pattern 
of COVID-19 disease progression, ranging from mild to fatal, therefore implies a heterogeneitiy of the immune response amongst SARS-CoV-2-infected individuals. In-depth knowledge on the immune response against SARS-CoV-2 and its relation to disease progression is still limited. Several studies described enhanced production of cytokines/chemokines such as IL-2, IL-6, TNF- $\alpha$ and CCL2, or impaired type-1 interferon (IFN) production to be associated with disease severity and/or unfavorable outcome [12-14]. Moreover, severe lymphocytopenia, including T-, CD4 T-, CD8 T-, and B-lymphocytes, have been linked to an unfavorable outcome $[3,12,15,16]$.

More detailed understanding of the immune status in relation to COVID-19 disease progression is crucial to understand the immunopathology, but may also result in the identification of prognostic immune biomarkers useful for patient stratification (high vs low risk of developing severe disease). Furthermore, although currently no effective treatment is available, immune biomarkers may also provide a rationale for future constructive treatment choices. Here, we performed comprehensive and integrated cellular and serological immune profiling in a Dutch cohort of COVID-19 patients with the aim of exploring the temporal dynamics of innate and adaptive immune activation in relation to disease progression and of determining immune biomarkers with potential prognostic and/or theranostic implications.

\section{METHODS}

\section{Patients}

Forty-four patients with a positive SARS-CoV-2 PCR test and diagnosis of COVID-19 were included between March $24^{\text {th }}-$ April $14^{\text {th }} 2020$ at the peripheral hospital Amphia Breda, the Netherlands. A detailed description of all individual patient characteristics is provided in table 1. Five patients were eventually admitted to the intensive care unit (ICU), of whom one directly upon hospital admission. The other 39 patients (mean age 71, SD 10.8; BMI 27.1 SD 5.1) were solely treated at the inpatient clinic. Three of five ICU admitted patients (mean age 75, SD 6.1; BMI 27.8 SD 3.9) eventually succumbed after a median hospital admission period of 11 days (range 4 - 14) and a median ICU stay of 8.9 days (range 1.4-13.0). These three patients (patients 1, 4, and 5; table 1 ) all had a history of underlying medical conditions. Two patients (patients 2 and 3; table 1) were still admitted to the ICU at the data cut ( $19^{\text {th }}$ of May; mean age 71 , SD 4.2; BMI 27.5 SD 2.1). Six (mean age 81, SD 4.4; BMI 24.2 SD 5.2) of 39 non-ICU patients succumbed after a median hospital admission period of 6.5 days (range 4.0-18.0; patients 6-11 table 1). Nonadmission to ICU was amongst others due to refusal by patients or based on joint decision to prevent complex lifesaving procedures and to focus on comfort-inducing endof-life care. Patients who recovered without ICU admission ( $n=33$; mean age 69, SD 10.5; BMI 27.7 SD 4.9) had a median hospital admission period of 7 days (range 2.0-18.0). To obtain a deeper understanding of the immune status of patients in relation to disease severity, patients were divided into a favorable (i.e. patients admitted to the inpatient clinic) or unfavorable group (i.e. patients admitted to the ICU department plus those who succumbed to disease). Group averages are presented in table 2.

Peripheral blood (PB) EDTA samples were collected from patients every three to four days for the entire hospitalization period and occasionally after hospital discharge. See figure 1 for an overview of onset of symptoms, patient admission, discharge, outcome, and sample collection. A small volume of the freshly obtained blood was used for flowcytometric immunophenotyping. Plasma was isolated within two hours after blood withdrawal and stored at $-20{ }^{\circ} \mathrm{C}$ for subsequent serological analysis.

The study was performed in accordance with the guidelines for sharing of patient data of observational scientific research in case of exceptional health situations, as issued by the Commission on Codes of Conduct of the Foundation Federation of Dutch Medical Scientific Societies (https://www.federa.org/ federa-english).

\section{Flowcytometric leukocyte analysis}

Two 8-color flowcytometric stainings were performed. Fifty $\mu$ of PB was incubated for 15 minutes at room temperature (RT) with antibodies (table 3), after which red blood cells were lysed. Flowcytometric data was acquired on a FACS Canto (BD Biosciences, Erembodegem, Belgium) instrument and analyzed using the Infinicyt software (Cytognos, Salamanca, Spain). Tube 1 was used to determine percentages of lymphocytes, gamma/delta T-lymphocytes, CD4 T-lymphocytes, and CD8 T-lymphocytes, relative to total leukocytes $\left(\mathrm{CD} 45^{+}\right)$. CD4 and CD8 T-lymphocytes were further subdivided into naive, central memory (CM), effector memory (EM), and terminally differentiated effector memory (TEMRA) T-lymphocytes based on CD27 and CD45RA expression. Tube 2 was used to determine the percentages of naive, CM, EM, and TEMRA CD4 or CD8 T-lymphocytes positive for the activation markers HLA-DR and/or CD56 relative to total leukocytes. Also, percentages of B-lymphocytes (CD3-, HLA-DR ${ }^{+}$), NK-cells (CD3-, HLA-DR ${ }^{-}$), monocytes, and neutrophils were determined relative to total leukocytes. Total numbers of lymphocyte subsets were calculated with the use of absolute leukocyte numbers from white blood cell differentiation count.

\section{Cytokine and soluble cell surface molecule analysis}

The following cytokines were measured: C-C motif chemokine ligand (CCL)2, CCL3, CCL4, CCL17, C$\mathrm{X}-\mathrm{C}$ motif chemokine ligand (CXCL)10, Fas ligand, Galectin-9, granulocyte-colony-stimulating factor (GCSF), granulocyte macrophage-colony stimulating factor (GM-CSF), IFN- $\gamma$, interleukin (IL)-1 $\beta$, IL-1 receptor antagonist (IL-1Ra), IL-6, IL-6 receptor $\alpha$ (IL-6R $\alpha$ ), IL-7, IL-8, IL-10, IL-12, IL-18, and tumor necrosis factor alpha (TNF- $\alpha$ ) using a Luminex 
Table 1

Patient characteristics.

\begin{tabular}{|c|c|c|c|c|c|c|c|c|c|c|}
\hline Patient & Age & Gender & BMI & $\begin{array}{l}\text { Symp onset } \\
\text {-hosp } \\
\text { (days) }\end{array}$ & $\begin{array}{l}\text { Hosp } \\
\text { - ICU } \\
\text { (days) }\end{array}$ & $\begin{array}{l}\text { ICU } \\
\text { (hours) }\end{array}$ & $\begin{array}{l}\text { Hosp- } \\
\text { outcome } \\
\text { (days) }\end{array}$ & Comorbidity & $\begin{array}{l}\text { Med (from } 4 \\
\text { wks before) }\end{array}$ & Outcome \\
\hline 1 & 70 & $\mathrm{~F}$ & 32.0 & 7 & 1 & 315 & 14 & $\begin{array}{l}\text { Hearth failure. } \\
\text { Diabetes }\end{array}$ & $\begin{array}{l}\text { Chloroquine. } \\
\beta \text {-blocker }\end{array}$ & Succumbed \\
\hline 2 & 68 & M & 29.0 & 14 & 4 & 552 & 56 & COPD & Chloroquine & Still admitted \\
\hline 3 & 74 & M & 26.0 & 19 & 0 & 528 & 51 & None & $\begin{array}{l}\text { Chloroquine. } \\
\text { ACE inhibitor }\end{array}$ & Still admitted \\
\hline 4 & 74 & $\mathrm{~F}$ & 27.2 & 4 & 2 & 214 & 11 & COPD & $\begin{array}{l}\text { Chloroquine. } \\
\text { Corticosteroids }\end{array}$ & Succumbed \\
\hline 5 & 82 & M & 24.3 & 18 & 2 & 33 & 4 & Hearth failure & $\begin{array}{l}\text { Chloroquine. } \\
\beta \text {-blocker. } \\
\text { Corticosteroids }\end{array}$ & Succumbed \\
\hline 6 & 80 & M & 19.7 & 8 & $\mathrm{n} / \mathrm{a}$ & $\mathrm{n} / \mathrm{a}$ & 6 & $\begin{array}{l}\text { COPD. Hearth } \\
\text { failure }\end{array}$ & $\begin{array}{l}\beta \text {-blocker. } \\
\text { Corticosteroids }\end{array}$ & Succumbed \\
\hline 7 & 87 & M & 31.6 & 4 & $\mathrm{n} / \mathrm{a}$ & $\mathrm{n} / \mathrm{a}$ & 7 & Kidney failure & $\begin{array}{l}\text { Chloroquine. } \\
\text { ACE inhibitor. } \\
\beta \text {-blocker }\end{array}$ & Succumbed \\
\hline 8 & 83 & M & 20.8 & Unknown & $\mathrm{n} / \mathrm{a}$ & $\mathrm{n} / \mathrm{a}$ & 18 & $\begin{array}{l}\text { COPD. Kidney } \\
\text { failure. Diabetes }\end{array}$ & Chloroquine & Succumbed \\
\hline 9 & 76 & $\mathrm{~F}$ & 27.9 & 14 & $\mathrm{n} / \mathrm{a}$ & $\mathrm{n} / \mathrm{a}$ & 4 & COPD & None & Succumbed \\
\hline 10 & 77 & $\mathrm{M}$ & 26.6 & 3 & $\mathrm{n} / \mathrm{a}$ & $\mathrm{n} / \mathrm{a}$ & 9 & COPD & Chloroquine & Succumbed \\
\hline 11 & 85 & $\mathrm{M}$ & 18.7 & 7 & $\mathrm{n} / \mathrm{a}$ & $\mathrm{n} / \mathrm{a}$ & 6 & Unknown & Unknown & Succumbed \\
\hline 12 & 71 & $\mathrm{M}$ & 29.3 & 4 & $\mathrm{n} / \mathrm{a}$ & $\mathrm{n} / \mathrm{a}$ & 4 & Diabetes & $\begin{array}{l}\text { Chloroquine. ACE } \\
\text { inhibitor. } \beta \text {-blocker }\end{array}$ & Recovered \\
\hline 13 & 73 & $\mathrm{M}$ & 30.1 & 4 & $\mathrm{n} / \mathrm{a}$ & $\mathrm{n} / \mathrm{a}$ & 4 & None & $\begin{array}{l}\text { Chloroquine. } \\
\text { Corticosteroids }\end{array}$ & Recovered \\
\hline 14 & 72 & $\mathrm{~F}$ & 41.1 & Unknown & $\mathrm{n} / \mathrm{a}$ & $\mathrm{n} / \mathrm{a}$ & 7 & Diabetes & $\beta$-blocker & Recovered \\
\hline 15 & 74 & $\mathrm{M}$ & 24.6 & 6 & $\mathrm{n} / \mathrm{a}$ & $\mathrm{n} / \mathrm{a}$ & 8 & COPD & Chloroquine & Recovered \\
\hline 16 & 67 & $\mathrm{M}$ & 25.2 & 10 & $\mathrm{n} / \mathrm{a}$ & $\mathrm{n} / \mathrm{a}$ & 4 & None & Chloroquine & Recovered \\
\hline 17 & 78 & $\mathrm{M}$ & 28.0 & 9 & $\mathrm{n} / \mathrm{a}$ & $\mathrm{n} / \mathrm{a}$ & 5 & Diabetes & $\begin{array}{l}\text { Chloroquine. } \\
\text { ACE inhibitor }\end{array}$ & Recovered \\
\hline 18 & 86 & $\mathrm{~F}$ & 21.9 & 7 & $\mathrm{n} / \mathrm{a}$ & $\mathrm{n} / \mathrm{a}$ & 4 & Hearth failure & $\begin{array}{l}\text { Chloroquine. } \\
\beta \text {-blocker }\end{array}$ & Recovered \\
\hline 19 & 87 & M & 23.7 & 14 & $\mathrm{n} / \mathrm{a}$ & $\mathrm{n} / \mathrm{a}$ & 5 & Hearth failure & $\begin{array}{l}\text { Chloroquine. ACE } \\
\text { inhibitor. } \beta \text {-blocker }\end{array}$ & Recovered \\
\hline 20 & 57 & M & 28.4 & 11 & $\mathrm{n} / \mathrm{a}$ & $\mathrm{n} / \mathrm{a}$ & 7 & None & Chloroquine & Recovered \\
\hline 21 & 52 & $\mathrm{~F}$ & 23.2 & 11 & $\mathrm{n} / \mathrm{a}$ & $\mathrm{n} / \mathrm{a}$ & 9 & None & $\beta$-blocker & Recovered \\
\hline 22 & 87 & $\mathrm{M}$ & 29.4 & 15 & $\mathrm{n} / \mathrm{a}$ & $\mathrm{n} / \mathrm{a}$ & 7 & COPD & $\begin{array}{l}\text { Chloroquine. } \\
\beta \text {-blocker. } \\
\text { Corticosteroids }\end{array}$ & Recovered \\
\hline 23 & 70 & $\mathrm{M}$ & 28.4 & 1 & $\mathrm{n} / \mathrm{a}$ & $\mathrm{n} / \mathrm{a}$ & 8 & None & None & Recovered \\
\hline 24 & 74 & $\mathrm{M}$ & 26.6 & 3 & $\mathrm{n} / \mathrm{a}$ & $\mathrm{n} / \mathrm{a}$ & 10 & None & $\begin{array}{l}\text { Chloroquine. } \\
\beta \text {-blocker }\end{array}$ & Recovered \\
\hline 25 & 80 & $\mathrm{M}$ & 23.0 & 13 & $\mathrm{n} / \mathrm{a}$ & $\mathrm{n} / \mathrm{a}$ & 3 & Diabetes & Chloroquine & Recovered \\
\hline 26 & 71 & $\mathrm{M}$ & 26.7 & 7 & $\mathrm{n} / \mathrm{a}$ & $\mathrm{n} / \mathrm{a}$ & 9 & Diabetes & $\begin{array}{l}\text { Chloroquine. } \\
\text { Corticosteroids }\end{array}$ & Recovered \\
\hline 27 & 73 & $\mathrm{M}$ & 23.6 & 10 & $\mathrm{n} / \mathrm{a}$ & $\mathrm{n} / \mathrm{a}$ & 7 & Diabetes & Chloroquine & Recovered \\
\hline 28 & 68 & $\mathrm{~F}$ & 41.6 & 8 & $\mathrm{n} / \mathrm{a}$ & $\mathrm{n} / \mathrm{a}$ & 13 & $\begin{array}{l}\text { Hearth \& kidney } \\
\text { failure. Diabetes }\end{array}$ & $\begin{array}{l}\text { Chloroquine. } \\
\text { Corticosteroids }\end{array}$ & Recovered \\
\hline 29 & 76 & $\mathrm{M}$ & 23.3 & 9 & $\mathrm{n} / \mathrm{a}$ & $\mathrm{n} / \mathrm{a}$ & 9 & COPD & $\begin{array}{l}\text { Chloroquine. } \\
\text { Corticosteroids }\end{array}$ & Recovered \\
\hline 30 & 56 & $\mathrm{M}$ & 30.5 & 10 & $\mathrm{n} / \mathrm{a}$ & $\mathrm{n} / \mathrm{a}$ & 3 & Unknown & Unknown & Recovered \\
\hline 31 & 79 & $\mathrm{M}$ & 24.6 & 14 & $\mathrm{n} / \mathrm{a}$ & $\mathrm{n} / \mathrm{a}$ & 4 & Unknown & Unknown & Recovered \\
\hline 32 & 53 & $\mathrm{~F}$ & Unknown & 10 & $\mathrm{n} / \mathrm{a}$ & $\mathrm{n} / \mathrm{a}$ & 10 & Unknown & Unknown & Recovered \\
\hline 33 & 69 & $F$ & 28.3 & 9 & $\mathrm{n} / \mathrm{a}$ & $\mathrm{n} / \mathrm{a}$ & 5 & Unknown & Unknown & Recovered \\
\hline 34 & 78 & $\mathrm{M}$ & 21.9 & 7 & $\mathrm{n} / \mathrm{a}$ & $\mathrm{n} / \mathrm{a}$ & 2 & None & Chloroquine & Recovered \\
\hline
\end{tabular}


Table 1

(Continued)

\begin{tabular}{|lllllllllll|}
\hline Patient & Age & Gender & BMI & $\begin{array}{l}\text { Symp onset } \\
\text {-hosp } \\
\text { (days) }\end{array}$ & $\begin{array}{l}\text { Hosp } \\
- \text { ICU } \\
\text { (days) }\end{array}$ & $\begin{array}{l}\text { ICU } \\
\text { (hours) }\end{array}$ & $\begin{array}{l}\text { Hosp- } \\
\text { outcome } \\
\text { (days) }\end{array}$ & Comorbidity & $\begin{array}{l}\text { Med (from 4 } \\
\text { wks before) }\end{array}$ & Outcome \\
\hline 35 & 66 & F & 28.3 & 8 & n/a & n/a & 2 & Hearth failure & $\begin{array}{l}\text { Chloroquine. } \\
\text { ACE inhibitor }\end{array}$ & Recovered \\
\hline 36 & 65 & M & 24.1 & 5 & n/a & n/a & 5 & None & Chloroquine & Recovered \\
\hline 37 & 71 & M & 31.2 & 10 & n/a & n/a & 7 & Unknown & Unknown & Recovered \\
\hline 38 & 69 & F & 27.4 & 13 & n/a & n/a & 5 & Unknown & Unknown & Recovered \\
\hline 39 & 53 & F & 26.8 & 8 & n/a & n/a & 9 & Unknown & Unknown & Recovered \\
\hline 40 & 77 & F & 26.5 & 14 & n/a & n/a & 10 & Unknown & Unknown & Recovered \\
\hline 41 & 73 & F & 24.7 & 9 & $\mathrm{n} / \mathrm{a}$ & $\mathrm{n} / \mathrm{a}$ & 10 & Unknown & Unknown & Recovered \\
\hline 42 & 52 & M & 28.4 & 12 & $\mathrm{n} / \mathrm{a}$ & $\mathrm{n} / \mathrm{a}$ & 10 & Unknown & Unknown & Recovered \\
\hline 43 & 56 & $\mathrm{~F}$ & 38.9 & 10 & $\mathrm{n} / \mathrm{a}$ & $\mathrm{n} / \mathrm{a}$ & 5 & Unknown & Unknown & Recovered \\
\hline 44 & 49 & $\mathrm{M}$ & 26.5 & 6 & $\mathrm{n} / \mathrm{a}$ & $\mathrm{n} / \mathrm{a}$ & 9 & Unknown & Unknown & Recovered \\
\hline
\end{tabular}

ACE: angiotensin converting enzyme; BMI: body mass index; COPD: chronic obstructive pulmonary disease; Hosp: hospital; ICU: intensive care unit; Med: medication; Symp: symptom; wks: weeks.

multiplex bead based assay (R\&D Systems Europe, Abingdon, United Kingdom). In addition, soluble (s) CD163 (ELISA, IQ Products, Groningen, the Netherlands) and sCD206 (ELISA, HycultBiotech, Uden, the Netherlands) were determined as measure for macrophage activation, whereas sIL-2R (Immulite, Siemens, Munich, Germany) was determined as measure of T-lymphocyte activation. All assays were performed according to the manufacturer's protocol.

\section{Antibodies to SARS-CoV-2}

Qualitative and differential detection of immunoglobulin (Ig)M and/or IgG antibodies to SARS-CoV-2 was performed on the patients' latest available plasma samples. For this purpose we used a COVID-19 IgG/ IgM rapid test cassette (Zhejiang Orient Gene Biotech Co Ltd, Huzhou, Zhejiang, China; kindly provided by A. Menarini diagnostics Benelux), with a reported sensitivity of $69 \%(\operatorname{IgM})$ and $93 \%(\operatorname{IgG})$ and specificity of $100 \%(\operatorname{IgM})$ and $99 \%(\operatorname{IgG})[17,18]$.

\section{Statistical analysis}

Differences in the presence of SARS-CoV-2-specific antibodies between patient groups were tested using a $\chi^{2}$ test.

The probability distribution of the vast majority of leukocyte subsets and serological parameters was distinctly right-skewed, and these were therefore logtransformed before further analyses. Cytokines IFN- $\gamma$, IL-10, and IL-12 were detected in less than $75 \%$ of the samples and were dichotomized. Samples below the limit of detection (LOD) for CCL3 (proportion below LOD $11 \%)$, GM-CSF (13\%), IL-1 $\beta$ (14\%), and IL-1Ra $(11 \%)$ were imputed by substituting estimated $\mathrm{LOD} / \sqrt{ } 2$. To reduce the effect of potential outliers in this relatively small dataset, we winsorized samples that were outside the "normal" range of the data, defined as the median \pm 2 times the absolute median deviation. The relation between cellular and serological parameters in samples collected at the first sampling moment ("baseline") and disease severity was investigated using logistic regression. In preliminary analyses age (but not sex, BMI, or the number of days between onset of symptoms and hospitalization) was found to be associated with disease severity, and thus was included in the models as a potential confounder.

We used mixed effect models to investigate potential different trajectories in cellular and serological parameters over time (days from the start of hospitalization) for patients with a favorable versus unfavorable outcome, allowing for the residual correlation between repeated observations using a random intercept and auto-regressive (AR1) correlation structure for each patient. $P$-values for the average intercepts and slope coefficients for patient groups with a favorable or unfavorable outcome were based on the usual Waldtests in models fitted using reduced maximum likelihood (REML), whereas between-group differences in these parameters were based on likelihood-ratio (LR)

Table 2

Patient group characteristics.

\begin{tabular}{|lllllll|}
\hline Group & $\begin{array}{l}\text { Mean } \\
\text { Age (SD) }\end{array}$ & $\begin{array}{l}\text { Male: } \\
\text { Female }\end{array}$ & $\begin{array}{l}\text { Mean } \\
\text { BMI (SD) }\end{array}$ & $\begin{array}{l}\text { Symp onset -Hospital } \\
\text { (Median days; range) }\end{array}$ & $\begin{array}{l}\text { Hospital-ICU } \\
\text { (Median days; range) }\end{array}$ & \% Comorbidity \\
\hline Favorable $(\mathrm{n}=33)$ & $69(11)$ & $21: 12$ & $28(5)$ & $9(1-15 ; \mathrm{n}=32)$ & $\mathrm{n} / \mathrm{a}$ & $62(\mathrm{n}=21)$ \\
\hline Unfavorable $(\mathrm{n}=11)$ & $78(6)$ & $8: 3$ & $26(5)$ & $8(3-19 ; \mathrm{n}=10)$ & $2(0-4 ; \mathrm{n}=5)$ & $82(\mathrm{n}=11)$ \\
\hline
\end{tabular}

BMI: body mass index; ICU: intensive care unit. 


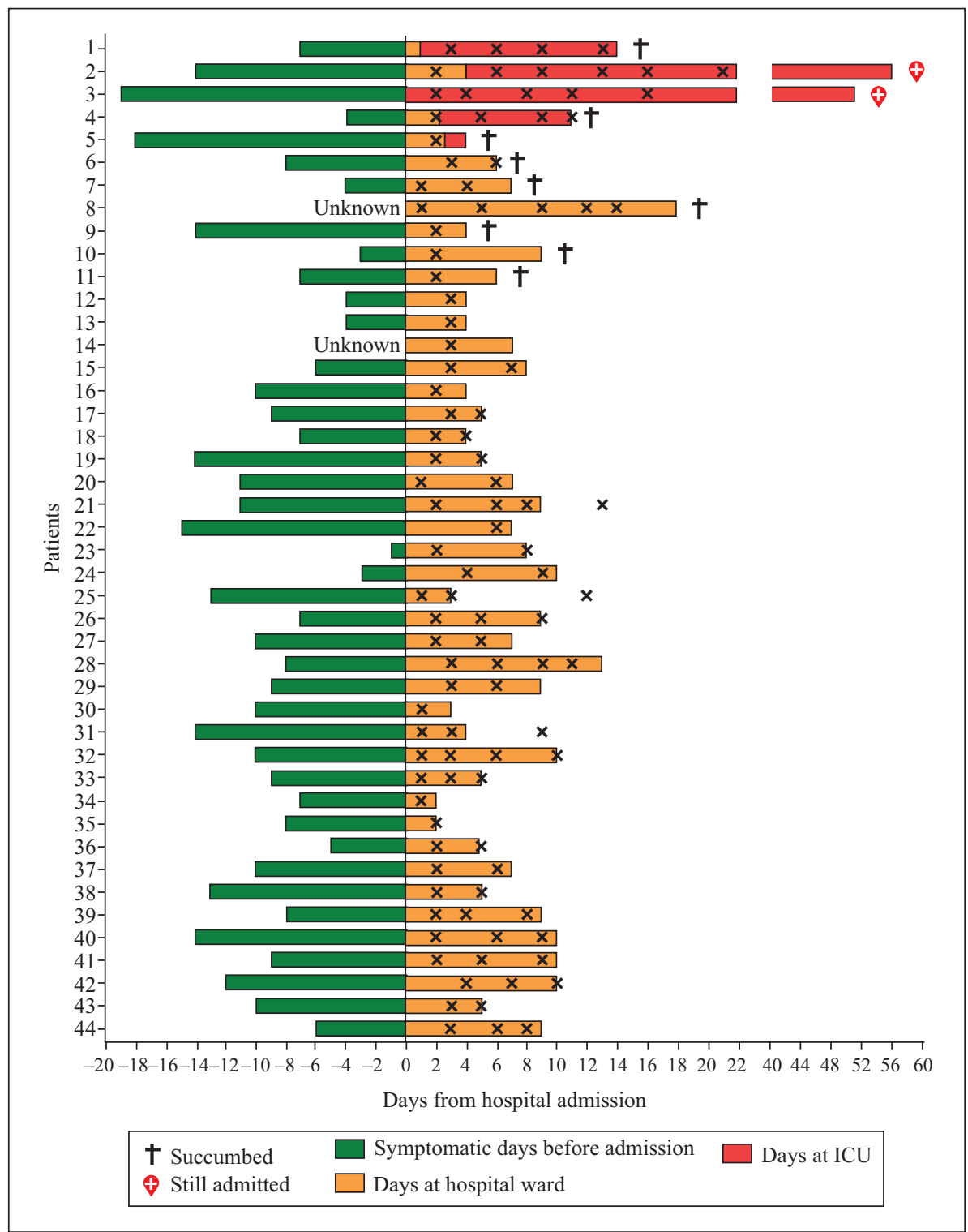

Figure 1

Schematic overview of all included patients. Green bars represent the symptomatic time before hospitalization, orange bars represent the time at the inpatient clinic, and red bars represent the time at the intensive care unit (ICU). X represents day of sample collection, $\dagger$ indicates the patient succumbed to the infection and white crosses indicate patients still admitted to the ICU at the end of the study.

testing after refitting the models using maximum likelihood (ML).

Separate models were estimated for each cellular and serological parameter, and FDR-adjusted $P$ values (q values) were estimated using the approach of Benjamini-Hochberg. Considering the explorative nature of this study with limited numbers of samples and high numbers of parameters, $P$-values and not q-values were used in the final analysis. All analyses were performed in $\mathrm{R}$ (version 4.0 [19]), using the lme function from the nlme package (version 3.1) to fit mixed effect models [20].

\section{RESULTS}

\section{Leukocyte subsets}

To characterize our COVID-19 cohort, we first determined PB leukocyte subset numbers within a maximum of four days after hospitalization (baseline $\mathrm{t}=0$ ). Both patients with a favorable and unfavorable outcome displayed total leukocyte numbers at the upper limit of the reference range (figure $2 A$ ). Although high leukocyte numbers were present, lymphocyte numbers were at the lower limit of the reference range for the favorable group and even below for the unfavorable group, although no significant difference between both groups was detected (figure 2B). High leukocyte numbers seemed to be caused by neutrophils, especially for patients with an unfavorable outcome as these displayed neutrophil numbers at the upper limit of the reference range (figure $2 C$ ). Though not significant, the unfavorable group displayed a higher neutrophil/lymphocyte ratio as compared with patients with a favorable outcome (figure $2 D$ ). In contrast, patients with an unfavorable outcome were more often monopenic, while PB of patients with a favorable outcome mostly contained normal monocyte 
Table 3

Antibodies tube 1 and 2.

\begin{tabular}{|llll|}
\hline Antibody target & Fluorochrome & Clone & Manufacturer \\
\hline Tube 1 & & & BD \\
\hline CD45 & V500 & H130 & BD \\
\hline CD3 & PerCP-Cy5.5 & SK7 & BD \\
\hline CD45RA & FITC & L48 & BD \\
\hline CD27 & APC & L128 & BD \\
\hline CD8 & APC-H7 & SK1 & BD \\
\hline CD4 & V450 & RPA-T4 & BC \\
\hline TCR- $\alpha \beta$ & PE & IP26A & BD \\
\hline TCR- $\gamma \delta$ & PE-Cy7 & 11F2 & BD \\
\hline Tube 2 & & & BD \\
\hline CD45 & V500 & H130 & BD \\
\hline CD3 & PerCP-Cy5.5 & SK7 & BD \\
\hline CD45RA & FITC & L48 & BD \\
\hline CD27 & APC & L128 & BD \\
\hline CD8 & APC-H7 & SK1 & BD \\
\hline HLA-DR & V450 & L243 & BD \\
\hline CD56 & PE & NCAM16.2 & L303.1 \\
\hline CD2 & PE-Cy7 & & \\
\hline
\end{tabular}

BD: Beckton Dickinson; BC: Beckman Coulter

numbers (figure 2E; $P=0.026$ ). T-lymphocytes, Blymphocytes, and natural killer cell numbers were at or below the lower limit of the reference range for both the favorable and unfavorable groups (figure $2 F-H$ ).

\section{T-lymphocyte subsets and activation status}

COVID-19 especially affects older ( $>60$ years of age) individuals. During aging changes in the immune system occur, which especially affect the cellular immune compartment that is critical during viral infections. Therefore, we analyzed T-lymphocyte subsets of both patient groups at baseline in more detail. Even though there were no significant differences in absolute CD4 and CD8 T-lymphocyte numbers between patients with a favorable or unfavorable outcome, both CD4 and CD8 T-lymphocyte numbers were clearly below the lower reference values of healthy individuals (figure $3 A$ ). When assessing CD4 and CD8 T-lymphocyte subsets (naive, CM, EM, and TEMRA), naive CD4 and CD8 Tlymphocyte numbers from both patients with a favorable and unfavorable outcome were below mean values of healthy controls [21]. Especially, the naive CD8 T-lymphocyte numbers seemed to be further decreased in the unfavorable group as compared with the favorable group, although this difference did not reach significance (figure $3 B$ ). While T-lymphocyte subset analysis only revealed trends between the favorable and unfavorable groups, substantial differences were observed in activation status of various CD8 T-lymphocyte subsets. Most prominently the naive and TEMRA compartment of patients in the unfavorable group displayed significantly decreased $\mathrm{CD}^{+} 6^{+}$
$\left(P=0.038\right.$ naive; $P=0.036$ TEMRA) and CD56 ${ }^{+}$ HLA-DR $^{+}(P=0.019$ naive; $P=0.029$ TEMRA $)$ cell numbers as compared with the favorable group (figure 3C). No such differences were seen in CD4 lymphocyte subsets.

\section{Serological parameters}

Induction, maintenance and immune direction are largely coordinated by soluble mediators (e.g. cytokines and chemokines), the controlled release of which is essential to prevent detrimental immunopathology. Since soluble parameters (e.g. C-reactive protein (CRP) and IL-6) have been described as possible prognostic markers during COVID-19 disease, we compared a broad range of soluble immunological parameters between our favorable and unfavorable COVID-19 patient groups. Overall, cytokine, sIL-2R, sCD163, and sCD206 concentrations were clearly above reference values (table 4, figure $4 A-F$ ). The unfavorable group displayed significantly increased plasma concentrations of CRP $(P=0.018)$, IL-6 $(P=0.009)$, CCL2 $(P=0.031), \quad$ CXCL10 $(P=0.005)$, and GM-CSF $(P=0.008)$ at baseline (figure $4 A-E)$. In contrast plasma concentrations of IL-7 were significantly $(P=0.047)$ decreased in the unfavorable group as compared with the favorable group (figure $4 F$ ). Of note, no significant differences were observed for the major inflammatory cytokines TNF- $\alpha$, IL-12, and IL-18 nor the neutrophil chemoattractant IL-8 (table 4).

\section{Longitudinal cellular and serological parameters}

From patients hospitalized for longer periods serial PB samples were obtained, which allowed us to monitor 


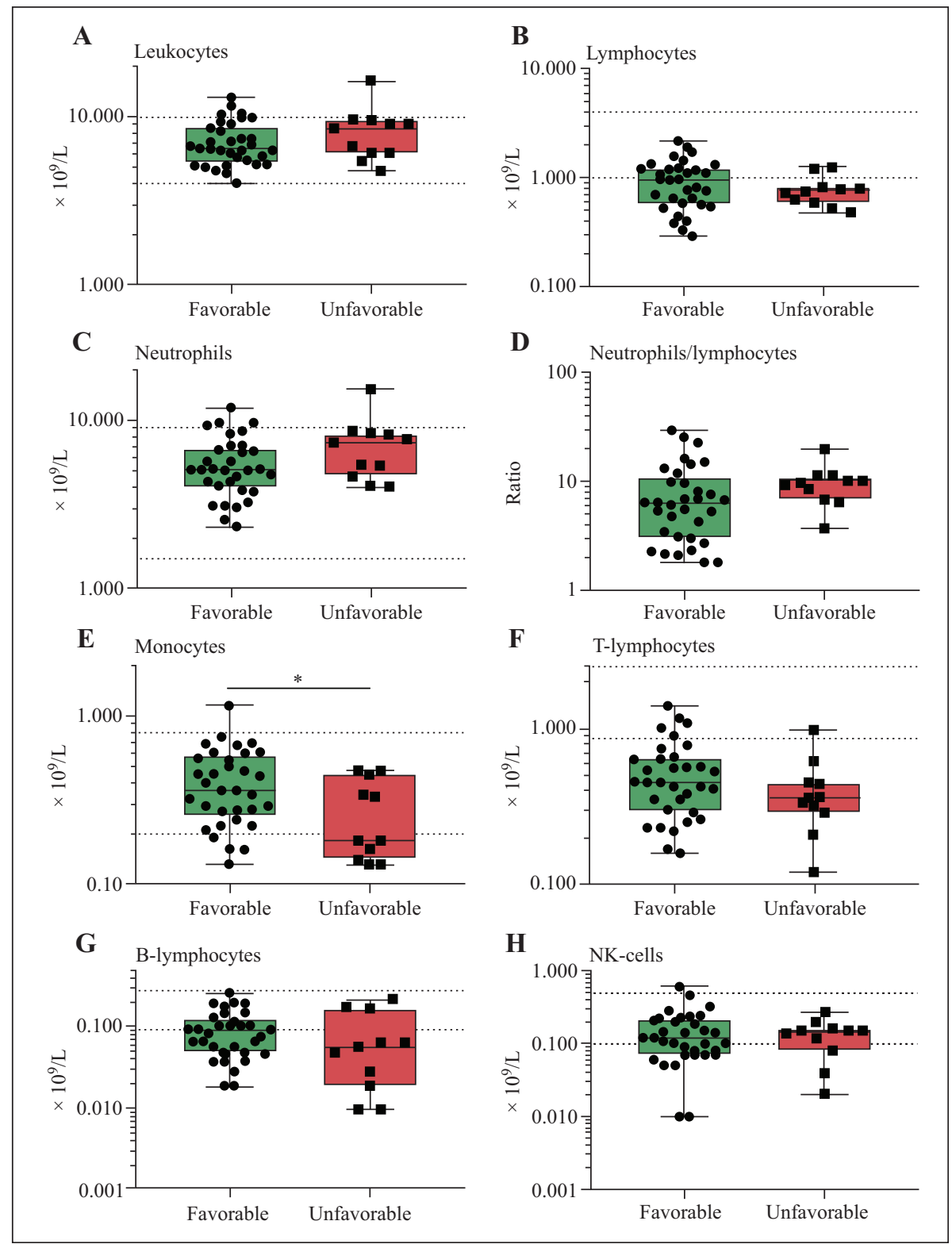

Figure 2

Leukocyte subset analysis at baseline. Both patients with a favorable or unfavorable outcome display high total leukocyte numbers (A) at the upper limit of the reference range while lymphocyte numbers (B) in both groups are below the lower limit of the reference range. The unfavorable group displays high neutrophil numbers (C) resulting in a high neutrophil/lymphocyte ratio (D). Significantly decreased monocyte numbers as compared with the favorable group (E) are observed. Both groups display Tlymphocyte and B-lymphocyte numbers $(F, G)$ below and NK cell numbers $(H)$ at the lower reference limit. Boxplots represent first and third quartile and median with whiskers representing the range. Horizontal dotted lines represent the upper and lower reference range. $*=P<0.05$. $P$-values derived from a logistic regression model of final status (favorable/unfavorable) on each subset parameter, adjusted for age. Favorable group $n=33$, unfavorable group $n=11$. Immune-cell subsets were obtained through Flow-cytometry.

the temporal dynamics of the immune response at cellular and serological levels.

At baseline, neutrophil numbers were increased in the unfavorable group as compared with patients with a favorable outcome (figure 2C). This difference tended to grow stronger over time as neutrophils in patients with an unfavorable outcome increased more strongly than in patients with a favorable outcome (figure $5 \mathrm{~A}$ ), although the difference was not statistically significant $(P=0.34)$. No significant changes were observed between the favorable and unfavorable groups regarding total leucocyte, lymphocyte, monocyte, gamma/ delta T-lymphocytes, B-lymphocyte, and NK-cell numbers (data not shown).
While reduced numbers of activated $\left(\mathrm{CD} 56^{+}\right.$and $\mathrm{CD}^{+} 6^{+} \mathrm{HLA}^{-D R^{+}}$) naive and TEMRA CD8 Tlymphocytes were observed at baseline (figure $3 C$ ), over time patients with an unfavorable outcome displayed a heterogeneous response, in some patients $\mathrm{CD} 56^{+}$and $\mathrm{CD} 6^{+} \mathrm{HLA}^{-\mathrm{DR}^{+}}$CD8 T-lymphocyte numbers did increase. However, this response was often delayed and less vigorous in patients with an unfavorable outcome and was sometimes not observed at all (TEMRA $\mathrm{CD}^{+} 6^{+}, \mathrm{CD}^{+} 6^{+} \mathrm{HLA}_{-\mathrm{DR}}^{+}$; naive CD56 ${ }^{+}, \mathrm{CD}^{+} 6^{+}$ $\mathrm{HLA}_{-\mathrm{DR}}^{+}$; figure $5 \mathrm{~B}, \mathrm{C}$, figure $\left.6 \mathrm{~A}, \mathrm{~B}\right)$. Even though no significant differences in levels of activated CD4 Tlymphocytes were observed at baseline, over time activated (HLA-DR ${ }^{+}$) CM and EM CD4 T-lympho- 


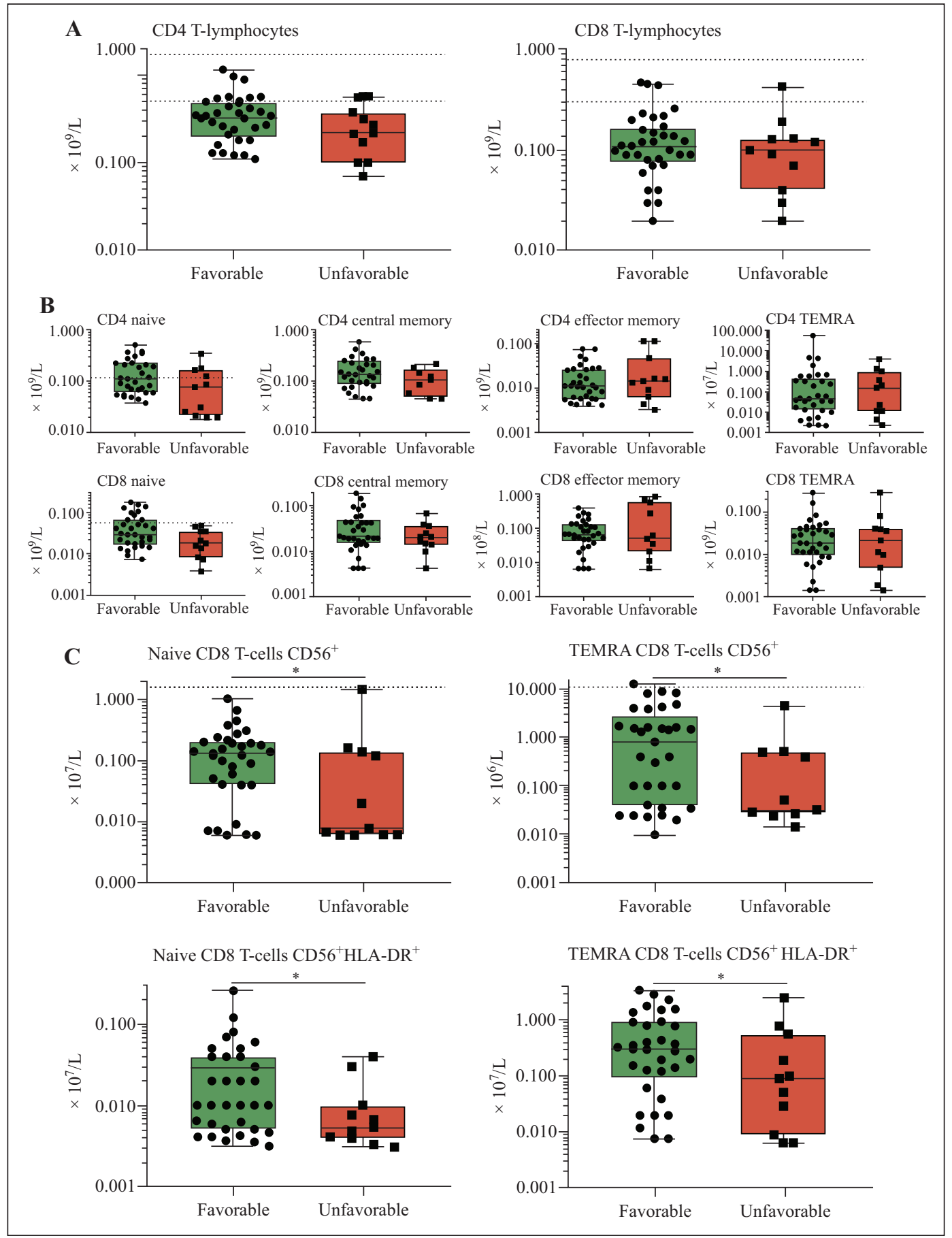

Figure 3

T-lymphocyte subset analysis at baseline. Both the favorable and unfavorable groups display CD4 and CD8 T-lymphocyte numbers below the reference range (A). The unfavorable group displayed a decreasing trend in CD4 and CD8 naive Tlymphocyte, no differences were detected for central memory (CM), effector memory (EM), and terminally differentiated effector memory (TEMRA) subset numbers (B). Significantly reduced activated $\left(\mathrm{CD} 56^{+}, \mathrm{CD}_{56}{ }^{+} \mathrm{HLA}^{-D R^{+}}\right)$naive and TEMRA CD8 Tlymphocytes were observed in the unfavorable group as compared with the favorable group (naive CD56 ${ }^{+}$, CD56 ${ }^{+} \mathrm{HLA}^{-D R}{ }^{+}$, TEMRA CD56 $\left.{ }^{+}, \mathrm{CD}_{5}{ }^{+} \mathrm{HLA}^{-D R}{ }^{+} ; \mathrm{C}\right)$. Boxplots represent first and third quartile and median with whiskers representing the range. Horizontal dotted lines represent the upper and lower reference range (A) or a mean value of healthy controls (B). $*=P<0.05 . P$ values derived from a logistic regression model of final status (favorable/unfavorable) on each subset parameter, adjusted for age. Favorable group $n=33$, unfavorable group $n=11$. Immune-cell subsets were obtained through Flow-cytometry.

cytes displayed a delayed response that was attenuated in the unfavorable group $\left(P_{\text {int }}=0.049, P_{\text {int }}<0.001\right.$; figure $5 D, E)$.

For serological parameters, the significant differences observed at baseline for CRP, IL-6, CCL2, CXCL10, and GM-CSF remained over time. Several serological parameters displayed a convalescent trend (CRP, IL-6, CXCL10, and GM-CSF) or remained stable at a moderate level (CCL2) in the favorable group. In contrast, in the unfavorable group these parameters either further increased (IL-6; $P<0.001$ ), remained stable at increased level (CRP; $P<0.001$, CCL2, GMCSF; $P=0.001)$, or decreased with delayed kinetics (CXCL10; $P=0.003$; figure $7 A-E$ ). Moreover, an inverse correlation existed between CCL2 and monocyte numbers (figure $7 F$ ). In most patients with an 
Table 4

Soluble parameters.

\begin{tabular}{|c|c|c|c|c|}
\hline Soluble parameter & Favorable Mean (SD) & Unfavorable Mean (SD) & Healthy control* Mean (SD) & Healthy control $10-90$ percentile \\
\hline CCL2 & $302.7(189.4)$ & $686.2(649.7)$ & $516.5(1018.0)$ & $175.8-597.8$ \\
\hline CCL3 & $196.6(100.2)$ & $250.1(44.0)$ & $94.7(85.9)$ & $0.0-203.3$ \\
\hline CCL4 & $262.3(60.9)$ & $295.2(40.6)$ & $164.8(63.8)$ & $128.3-190.9$ \\
\hline CCL17 & $380.9(290.2)$ & $496.7(404.0)$ & $522.9(460.0)$ & $205.9-939.4$ \\
\hline CXCL10 & $412.7(416.8)$ & $1061.2(518.9)$ & $81.4(332.9)$ & $6.6-59.0$ \\
\hline FASL & $25.1(10.0)$ & $21.7(7.9)$ & $29.4(8.7)$ & $16.6-40.0$ \\
\hline G-CSF & $192.3(93.5)$ & $205.3(74.4)$ & $67.0(13.7)$ & $49.0-84.4$ \\
\hline Galectin-9 & $32712.1(14699.2)$ & $32594.1(8051.2)$ & $8786.5(17520.8)$ & $2535.7-13454.5$ \\
\hline GM-CSF & $11.4(9.3)$ & $30.2(15.6)$ & $2.0(8.3)$ & $0.0-2.0$ \\
\hline IFN- $\gamma$ & $9.6(16.9)$ & $15.3(12.0)$ & $1.1(5.1)$ & $0.0-0.7$ \\
\hline IL-1 $\beta$ & $4.1(5.0)$ & $5.1(2.3)$ & $0.6(1.7)$ & $0.0-1.2$ \\
\hline IL1-R $\alpha$ & $4502.9(3394.1)$ & $5915.4(3030.8)$ & $355.7(228.2)$ & $162.9-670.3$ \\
\hline IL-6 & $28.8(40.8)$ & $91.7(83.6)$ & $8.8(34.6)$ & $1.2-6.3$ \\
\hline IL-7 & $9.4(5.3)$ & $6.9(2.1)$ & $5.9(2.8)$ & $3.7-8.5$ \\
\hline IL-8 & $8.4(4.2)$ & $7.8(2.3)$ & $14.9(37.1)$ & $4.1-19.1$ \\
\hline IL-10 & $9.5(9.8)$ & $22.2(12.0)$ & $1.8(3.1)$ & $0.0-4.3$ \\
\hline IL-12p70 & $16.5(14.2)$ & $75.4(75.6)$ & $5.5(18.9)$ & $0.0-11.2$ \\
\hline IL-18 & $1050.5(766.1)$ & $1002.6(731.5)$ & $433.8(1071.0)$ & $140.2-425.6$ \\
\hline IL-6R $\alpha$ & 36037.0 (8571.6) & 31647.3 (7318.6) & $29639.8(7205.0)$ & $19638.4-38181.9$ \\
\hline $\mathrm{TNF} \alpha$ & $5.0(1.9)$ & $6.1(2.1)$ & $3.2(2.2)$ & $2.0-4.0$ \\
\hline sIL2R & $1690.0(214.2)$ & $2171.5(2419.0)$ & 337 (105) & $171-553$ \\
\hline CD206 & $904.2(526.9)$ & $1486.8(1344.9)$ & $157.4(80.5)$ & $48.5-256.0$ \\
\hline CD163 & $129.6(526.9)$ & $1262.1(606.1)$ & $752.7(236.3)$ & $473.8-982.5$ \\
\hline
\end{tabular}

CCL: C-C motif chemokine ligand; CXCL: C-X-C motif chemokine ligand; G-CSF: Granulocyte stimulating factor; GM-CSF: Granulocyte macrophage colony stimulating factor; IFN: interferon; IL: interleukin; TNF: tumor necrosis factor. All values are depicted in pg/ml; with the exception of sIL2R; which is depicted in iu/ ml. * Healthy control serum $(n=22)$ was obtained with the approval of the local medical ethical committee (MEC-nr.2016-202).

unfavorable outcome IFN- $\gamma$ remained measurable over time, whereas it became undetectable in most patients with a favorable outcome ( $P=0.043$; data not shown).

\section{SARS-CoV-2 targeting IgM and IgG}

To further study the initiation of an adaptive immune response over time, we measured the presence of SARS-CoV-2 antibodies in plasma taken at the latest sampling point of each patient. Applying a point-ofcare test to identify the presence of $\operatorname{IgM}$ and/or IgG SARS-CoV-2 specific antibodies resulted in an overall sensitivity of $88,6 \%$ (39 out of 44 ). In thirty-seven out of 44 COVID-19 cases, IgM was detected, whereas IgG was detected in 38 cases. Association of the presence of SARS-CoV-2-specific antibodies to disease outcome revealed absence of both $\operatorname{IgM}$ and $\operatorname{IgG}(\mathrm{n}=3)$ or $\operatorname{IgG}$ only $(n=1)$ in 4 out of 11 patients with an unfavorable outcome $(36,4 \%)$ and absence of both IgM and IgG in 2 out of 33 patients with a favorable outcome $(6,1 \%$; $\chi^{2}$-test $\left.P=0.04\right)$.

\section{DISCUSSION}

Here, we present a study of 44 hospitalized patients of Dutch Caucasian origin with COVID-19 in which we analyzed a broad range of cellular and serological immune parameters in association with disease severity and progression.

In concordance with previous studies from Asia $[22,23]$, COVID-19 patients with an unfavorable outcome displayed more profound leukocytosis and neutrophilia, which together with lymphopenia resulted in higher neutrophil/lymphocyte ratios. Soluble markers measured were largely in line with previous literature, as high serum CRP, IL-6, CCL2, CXCL10, and GM-CSF levels have been correlated with an unfavorable outcome [22-24]. Hence, these data indicate that cellular and inflammatory mediator responses during COVID-19 are generally comparable between Asian and Caucasian individuals and confirm the validity of the patient cohort used in this study. Interestingly, we observed that patients with an unfavorable outcome had lower circulating levels of IL-7, a cytokine critical for immune homeostasis and maintenance of immune fitness [25]. In addition, by studying the temporal dynamics of cellular and serological immune parameters during COVID-19, we found evidence for a dysregulated adaptive immune response in patients with an unfavorable outcome. A rapid innate immune response, followed by a strong adaptive response along with dampened innate immune activation, is essential to overcome infectious disease without excessive tissue damage [26]. Albeit 


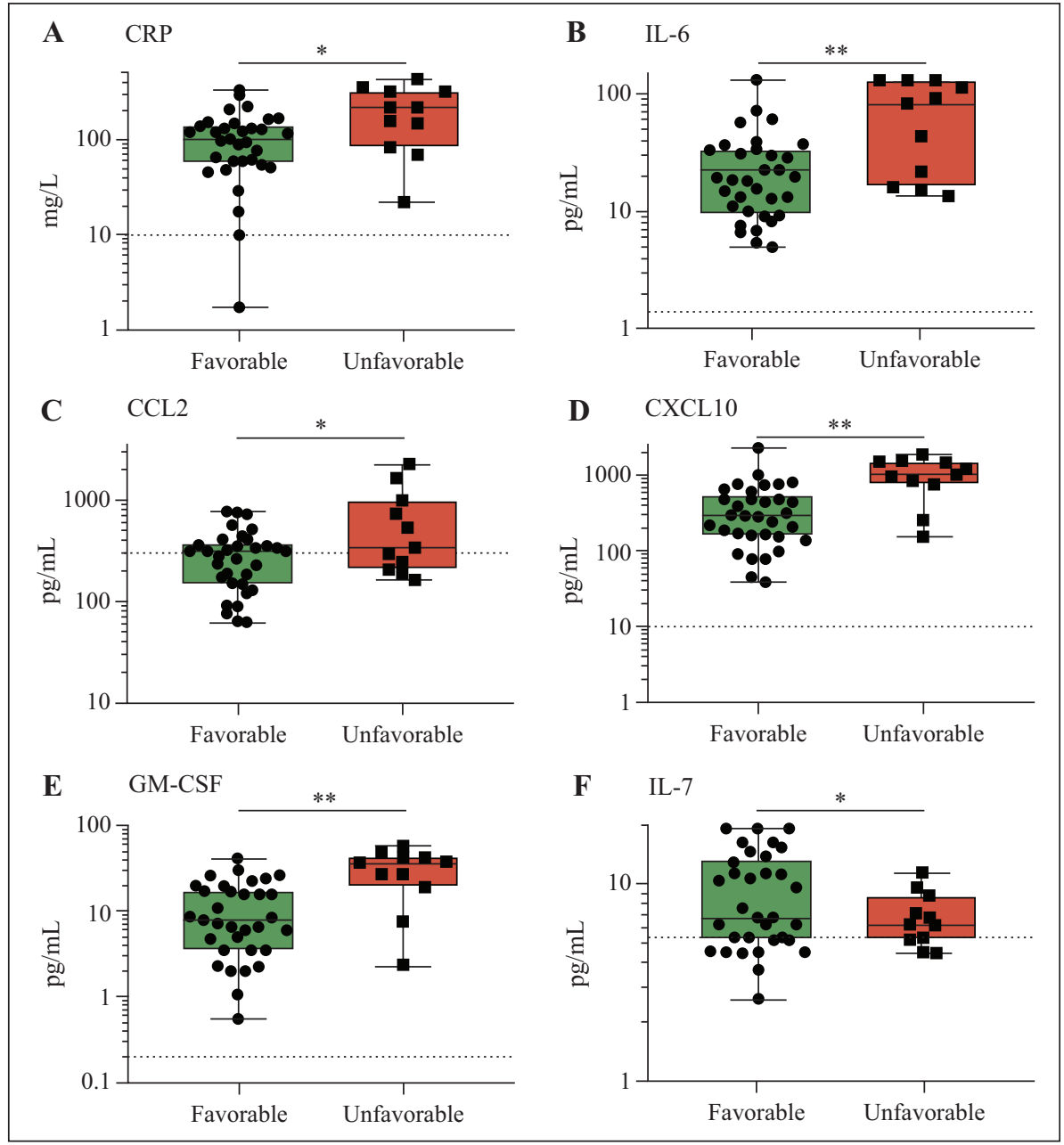

Figure 4

Soluble serological parameters at baseline. C-reactive protein (CRP) was measured by turbidimetric analysis, significantly increased CRP (A) was present in plasma from patients with an unfavorable outcome as compared with patients with a favorable outcome. Luminex multiplex bead based analysis was applied to detect cytokine and chemokine plasma levels. Patients with an unfavorable outcome displayed significantly increased levels of interleukin (IL)-6 (B), C-C motif chemokine ligand (CCL)2 (C), C-X-C motif chemokine ligand (CXCL)10 (D), and granulocyte macrophage colony stimulating factor (GM-CSF; E). In contrast IL-7 plasma levels were significantly decreased in the unfavorable group as compared with patients with a favorable outcome (F). Boxplots represent first and third quartile and median with whiskers representing the range. Horizontal dotted lines represent the mean of healthy controls. $*=P<0.05, * *=P<0.01$. $P$ values derived from a logistic regression model of final status (favorable/ unfavorable) on each subset parameter, adjusted for age. Favorable group $\mathrm{n}=33$, unfavorable group $\mathrm{n}=11$.

overall lymphocyte subsets decrease during COVID19, lymphopenia develops mostly through a decrease of CD4 and CD8 T-lymphocytes, indicating a delayed or defective cellular adaptive immune response in these patients [13]. Nonetheless, we cannot rule out that this decrease in circulating CD4 and CD8 lymphocytes is related to enhanced recruitment into the lungs or apoptosis, as postulated by others [27, 28]. Further indepth T-lymphocyte subset analyses revealed that this difference is related to a strong decline in circulating numbers of naive T-lymphocytes. A decrease in naive T-lymphocytes, resulting from reduced thymopoiesis or peripheral homeostatic proliferation, is a main feature of immuno-senescence [25, 29-31]. Obesity, another risk factor for severe COVID-19, is also associated with T-lymphocyte alterations, including reduced thymopoiesis and subsequent reduced peripheral naive T-lymphocytes [30, 31]. Nevertheless, it has been proposed that relatively healthy obese individuals might compensate for this by increasing peripheral homeostatic proliferation, driven by cytokines such as IL-7 and CCL5 amongst others [32].
Hypercytokinemia has been associated with unfavorable COVID-19 outcome. This may relate to prolonged innate immune activation resulting in increased inflammatory cytokine levels. Our finding of elevated circulating sCD163 and sCD206 further supports the notion that excessive macrophage activation contributes to COVID-19 disease severity. CCL2 is a potent chemo-attractant for monocytes/macrophages that, through CC chemokine receptor 2 (CCR2) binding home toward sites of disturbed tissue homeostasis [33]. Considering the strong inverse correlation of CCL2 levels and absolute numbers of monocytes in $\mathrm{PB}$ of patients with an unfavorable outcome (figure $7 F$ ), together with high levels of IL-6 and CRP, suggests increased innate immune activation. This is further strengthened by the observation that bronchoalveolar lavage fluid from severe COVID-19 patients contains increased numbers of pro-inflammatory monocytederived macrophages [34]. The low numbers of monocytes that we observed in the PB could thus be due to enhanced migration of these cells to the lung tissue. 
A Neutrophils

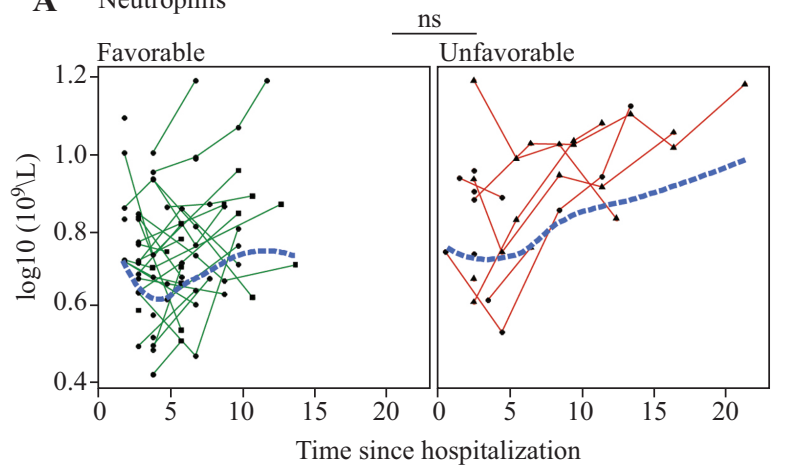

B TEMRA CD8 T-lymphocytes CD56 ${ }^{+}$
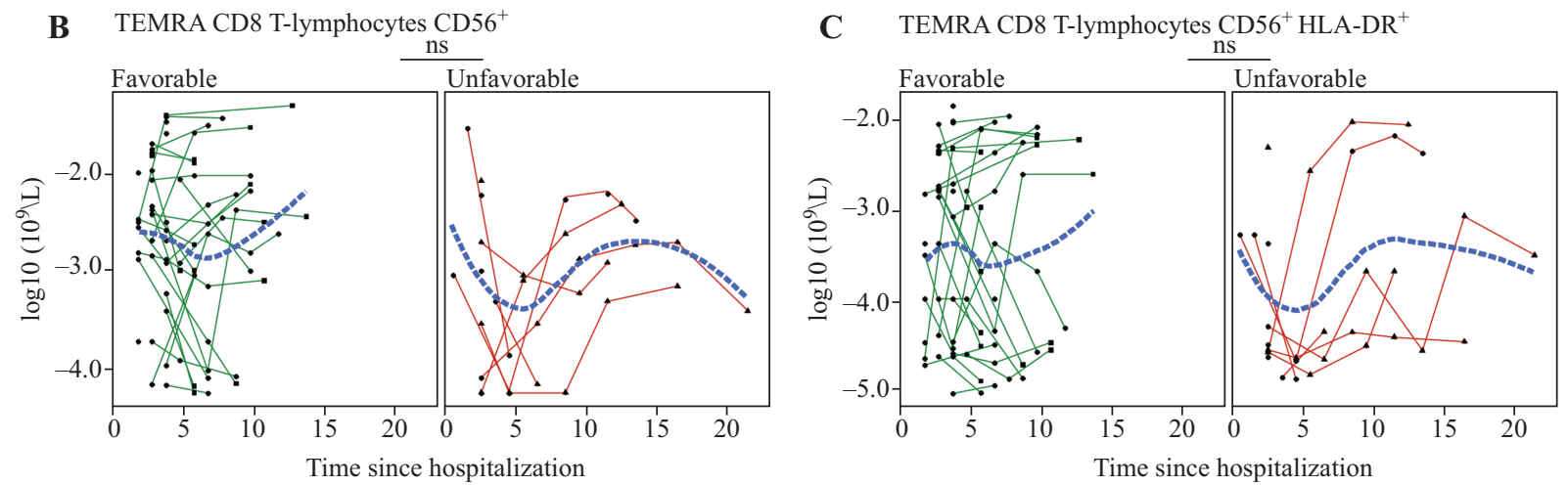

D CM CD4 T-lymphocytes HLA-DR
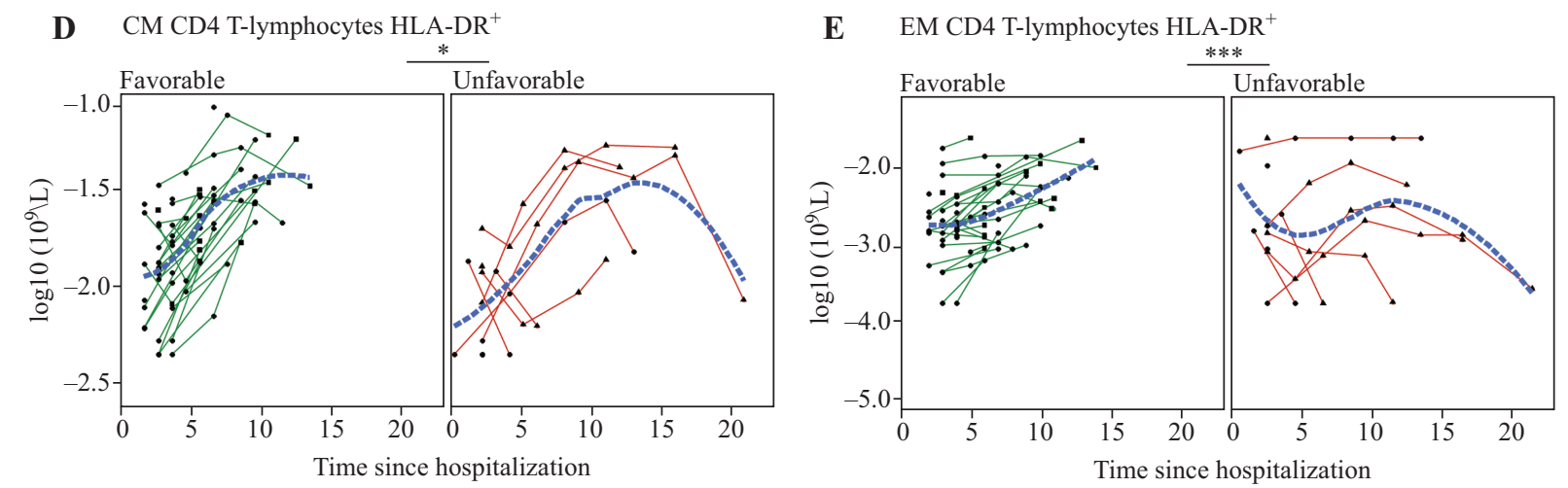

State: Hospitalized $\boldsymbol{\Delta}$ Unfavorable $\boldsymbol{\square}$ Favorable

Figure 5

Longitudinal cellular analyses. Serial peripheral blood (PB) samples were obtained from patients hospitalized for longer periods and were used to monitor the temporal dynamics of the immune response. Over time neutrophil numbers further increased in patients with an unfavorable outcome while decreasing or remaining stable in patients with a favorable outcome (A). Over time activated $\left(\mathrm{CD}^{2} 6^{+}, \mathrm{CD} 56^{+} \mathrm{HLA}^{\left.-D R^{+}\right)}\right.$TEMRA CD8 T-lymphocyte numbers remained lower or displayed a delayed response in patients with an unfavorable outcome (B,C). Over time activated (HLA-DR $\left.{ }^{+}\right)$CM and EM CD4 T-lymphocyte numbers displayed a delayed response in patients with an unfavorable outcome $(\mathrm{D}, \mathrm{E}) *=P<0.05, * * *=P<0.001$. $P$-values derived from a mixed model analyses for each cellular parameter, stratified by final status (favorable/unfavorable) and adjusted for age. Favorable group $\mathrm{n}=33$, unfavorable group $\mathrm{n}=11$.

Of note, even though we do recognize limitations in our study design, including variations in the collection time of the baseline samples, small sample size, and relatively long time between subsequent samples which may have resulted in missing rapid changes in mediators, baseline results are largely reflected by longitudinal analysis underlining the validity of presented baseline results. Despite small numbers and relatively long intervals, serial sampling in our COVID-19 patients over time allowed us to monitor the immune kinetics and to obtain more insight into disease biology. Our cellular analyses are suggestive of a delayed cellular adaptive immune response, which remains stationary for a prolonged time before normalizing in patients with an unfavorable outcome. The fact that CXCL10 and GM-CSF display a more gradual decrease in the unfavorable group further substantiates this idea, since delayed/inefficient activation of the adaptive immune system will hamper viral clearance and may result in secondary tissue damage. Along this line, $36 \%$ of patients with unfavorable outcome did not produce SARS-CoV-2-specific antibodies, which underlines the protective nature of the SARS-CoV-2 antibody response in the favorable group. Furthermore, the continuously high and/or increasing levels of CRP, IL-6, and neutrophil numbers support occurrence of immune-mediated tissue damage due to sustained activation of the innate 


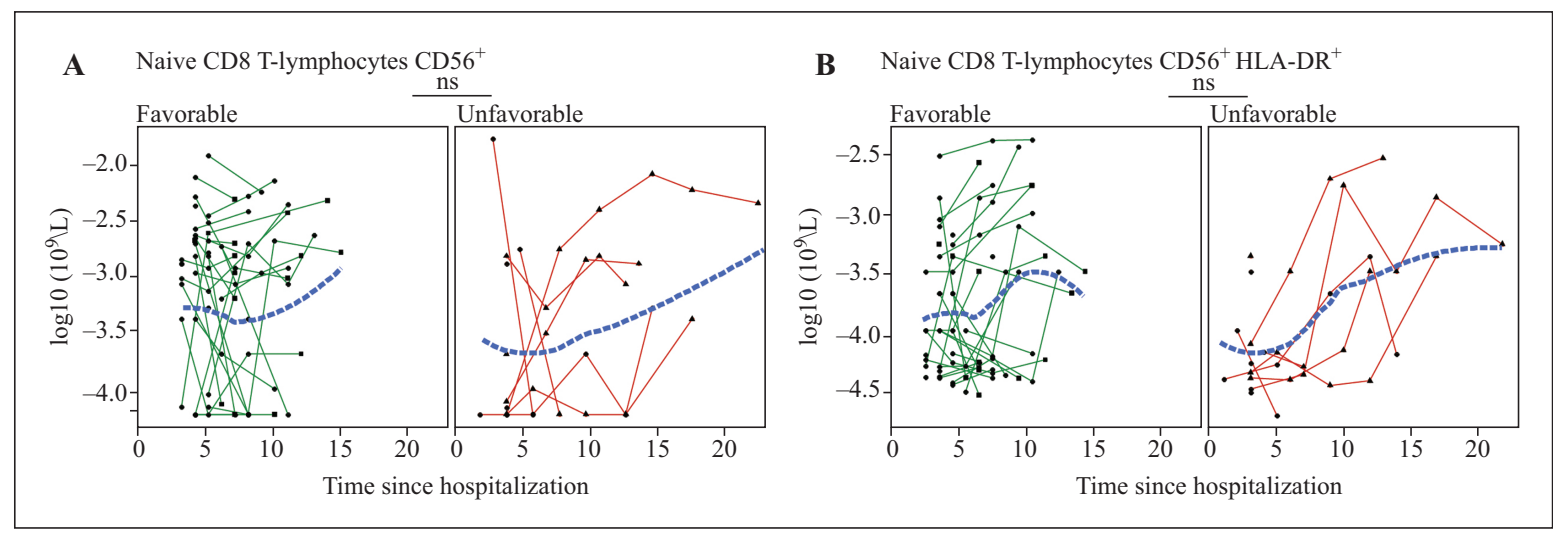

Figure 6

Longitudinal cellular analyses. Over time activated $\left(\mathrm{CD} 56^{+}, \mathrm{CD} 56^{+} \mathrm{HLA}^{-\mathrm{DR}}{ }^{+}\right)$naive $\mathrm{CD} 8 \mathrm{~T}$-lymphocyte numbers remained lower or displayed a delayed response in patients with an unfavorable outcome $(\mathrm{A}, \mathrm{B})$. Favorable group $\mathrm{n}=33$, unfavorable group $\mathrm{n}=11$.

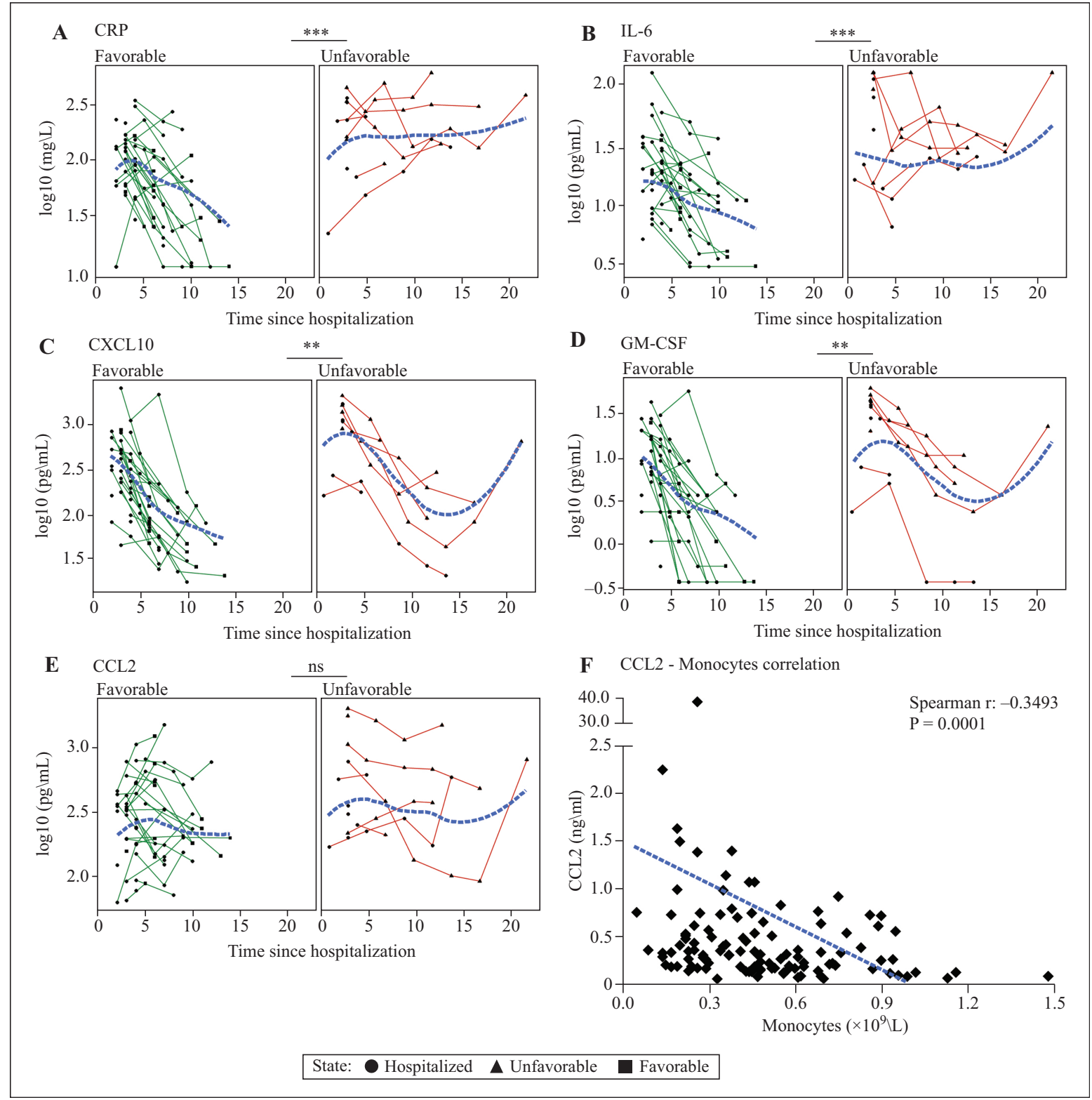

Figure 7

Longitudinal serological analyses. Over time patients with an unfavorable outcome displayed a significant further increase of plasma CRP levels (A) while IL-6 (B) remained at a heightened level and CXCL10 (C) decreased at a slower pace compared to patients with a favorable outcome. GM-CSF plasma levels rapidly declined in patients with a favorable outcome while levels declined with delayed kinetic in patients with an unfavorable outcome (D). CCL2 remained stable at high levels (E), plasma levels correlated inversely with absolute numbers of monocytes (F). ${ }^{* *}=P<0.01, * * *=P<0.001$. $P$-values derived from mixed model analyses for each serological parameter, stratified by final status (favorable/unfavorable) and adjusted for age. Favorable group $\mathrm{n}=33$, unfavorable group $\mathrm{n}=11$. 
immune responses. Although we did not include type-1 IFN measurements in our study due to technical reasons, effective innate responses to viral infections are highly dependent on these cytokines, as they directly interfere with viral replication, induce viral resistance in uninfected cells, and enhance viral protein presentation to eradicate viral infected cells. Previous studies reported inappropriate type-1 IFN responses or the presence of type-1 IFN targeting autoantibodies in severe COVID-19 patients $[35,36]$, indicating these as potentially interesting biomarkers to discriminate between patients with an unfavorable or favorable outcome.

Our current data and those from others provide great insight into potential theranostic markers in an era in which biologicals and small molecule inhibitors are available for many targets. To this extent, patients who are admitted for longer time periods and show prolonged innate immune activation could be treated with various molecules. In potential, the main drivers of the pro-inflammatory response could be blocked, such as IL-6 with tociluzumab (NCT04320615) or GM-CSF with lenzilumab (NCT04351152) [37, 38]. On the other hand, as more and more evidence arises that pathological macrophages in the lung tissue are derived from circulating monocytes, blocking CCR2 with cenicriviroc or CCR5 with leronlimab might be advantageous as well [39]. We observed lower circulating IL-7 in COVID-19 patients with unfavorable outcome, which may be a rationale for IL-7 treatment early during disease course, as IL-7 has been shown to selectively boost and rejuvenate CD4 and CD8 Tlymphocytes and increase immune-repertoire diversity [40]. Nevertheless, the latter should be considered with caution, since IL-7 may also reduce regulatory T-lymphocytes [41].

In conclusion, the data obtained in our cohort seem to suggest that heightened and sustained innate immune activation in COVID-19 patients with an unfavorable disease course results in a delayed and ineffective adaptive immune response. In turn, this would lead to ineffective viral clearance, sustained inflammation, and continued recruitment of monocytes to the lung, which together with increasing numbers of neutrophils could result in excessive tissue damage. Although our findings should be validated in larger patient cohorts, they provide an interesting concept for future studies and offer avenues for therapeutic choices.

Acknowledgements. We gratefully acknowledge Ms R. van Rijckevorsel for performing all flowcytometric analyses. We gratefully acknowledge Ms Nicole Nagtzaam and Ms Marja Smits-te Nijenhuis for their technical support.

Author contributions: B.S. and J.L.J.C. performed the experiments, analyzed the data, interpreted results, and wrote the manuscript; A.J.G., P.H. and T.A.A.M.E. collected the samples, interpreted results, and helped writing the manuscript; R.C.H.V. and L.P. performed the statistical analyses and helped writing the manuscript; A.W.L., W.A. D., and V.H.J.V. designed the study, interpreted results, and helped writing the manuscript. Conflicts of interest: none.
Data sharing statement: The data that support the findings of this study are available from the corresponding author upon reasonable request. Ethical statement: The study was performed in accordance with the guidelines for sharing of patient data of observational scientific research in case of exceptional health situations, as issued by the Commission on Codes of Conduct of the Foundation Federation of Dutch Medical Scientific Societies (https:// www.federa.org/federa-english).

\section{REFERENCES}

1. Lescure FX, Bouadma L, Nguyen D, et al. Clinical and virological data of the first cases of COVID-19 in Europe: a case series. Lancet Infect Dis 2020; 20(6):697-706.

2. Gu X, Cao B, Wang J. Full spectrum of COVID-19 severity still being depicted - Authors' reply. Lancet 2020; 395 (10228):948.

3. Huang C, Wang Y, Li X, et al. Clinical features of patients infected with 2019 novel coronavirus in Wuhan, China. Lancet 2020; 395(10223):497.

4. Liu K, Fang YY, Deng Y, et al. Clinical characteristics of novel coronavirus cases in tertiary hospitals in Hubei Province. Chin Med $J$ 2020; 133(9):1025.

5. Wang $\mathrm{D}, \mathrm{Hu} \mathrm{B}, \mathrm{Hu} \mathrm{C}$, et al. Clinical characteristics of 138 hospitalized patients with 2019 novel coronavirusinfected pneumonia in Wuhan, China. JAMA 2020; 323 (11):1061-9.

6. Zheng Z, Peng F, Xu B, et al. Risk factors of critical \& mortal COVID-19 cases: a systematic literature review and metaanalysis. J Infect 2020; 81(2):e16-25.

7. Li X, Xu S, Yu M, et al. Risk factors for severity and mortality in adult COVID-19 inpatients in Wuhan. J Allergy Clin Immunol 2020; 146(1):110-8.

8. Lighter J, Phillips M, Hochman S, et al. Obesity in patients younger than 60 years is a risk factor for Covid-19 hospital admission. Clin Infect Dis 2020; 71(15):896-7.

9. Shieh WJ, Hsiao CH, Paddock CD, et al. Immunohistochemical, in situ hybridization, and ultrastructural localization of SARSassociated coronavirus in lung of a fatal case of severe acute respiratory syndrome in Taiwan. Hum Pathol 2005; 36 (3):303.

10. Zhou P, Yang XL, Wang XG, et al. A pneumonia outbreak associated with a new coronavirus of probable bat origin. Nature 2020; 579(7798):270.

11. Hoffmann M, Kleine-Weber H, Schroeder S, et al. SARS -CoV-2 cell entry depends on ACE2 and TMPRSS2 and is blocked by a clinically proven protease inhibitor. Cell 2020; 181 (2): 271 .

12. Hadjadj J, Barnabei L, Corneau A, et al. Impaired type I interferon activity and exacerbated inflammatory responses in severe Covid-19 patients. MedRxiv 2020; 369(6504):718-24.

13. Qin $\mathrm{C}$, Zhou $\mathrm{L}, \mathrm{Hu} \mathrm{Z}$, et al. Dysregulation of immune response in patients with COVID-19 in Wuhan, China. Clin Infect Dis 2020; 71(15):762-8.

14. Herold T, Jurinovic V, Arnreich C, et al. Elevated levels of interleukin-6 and CRP predict the need for mechanical ventilation in COVID-19. J Allergy Clin Immunol 2020; 146 (1):128-136.e4.

15. Ruan Q, Yang K, Wang W, Jiang L, Song J. Clinical predictors of mortality due to COVID-19 based on an analysis of data of 150 patients from Wuhan, China. Intensive Care Med 2020; 46 (5):846. 
16. Wang F, Nie J, Wang H, et al. Characteristics of peripheral lymphocyte subset alteration in Covid-19 pneumonia. J Infect Dis 2020; 221(11):1762.

17. Hoffman T, Nissen K, Krambrich J, et al. Evaluation of a COVID-19 IgM and IgG rapid test; an efficient tool for assessment of past exposure to SARS-CoV-2. Infect Ecol Epidemiol 2020; 10(1):1754538.

18. Li Z, Yi Y, Luo X, et al. Development and clinical application of a rapid IgM-IgG combined antibody test for SARS-CoV-2 infection diagnosis. J Med Virol 2020; 92(9):151824.

19. Team RC. A language and environment for statistical computing. $\mathrm{R}$ Foundation for Statistical Computing, Vienna, Austria. http://www.R-project.org/

20. Pinheiro J, Bates D, DebRoy S, Sarkar D, Eispack HS, Van Willigen B, R Core Team. nlme: linear and nonlinear mixed effects models. $R$ package version 3.1-144. 2020.

21. Provinciali M, Moresi R, Donnini A, Lisa RM. Reference values for CD4+ and CD8+ T lymphocytes with naive or memory phenotype and their association with mortality in the elderly. Gerontology 2009; 55(3):314.

22. Chen G, Wu D, Guo W, et al. Clinical and immunological features of severe and moderate coronavirus disease 2019. J Clin Invest 2020; 130(5):2620.

23. Wu C, Chen X, Cai Y, et al. Risk factors associated with acute respiratory distress syndrome and death in patients with coronavirus disease 2019 pneumonia in Wuhan, China. JAMA Intern Med 2020; 180(7):934-43.

24. Mehta P, McAuley DF, Brown M, et al. COVID-19: consider cytokine storm syndromes and immunosuppression. Lancet 2020; 395(10229):1033.

25. Nguyen V, Mendelsohn A, Larrick JW. Interleukin-7 and Immunosenescence. J Immunol Res 2017; 2017 : 4807853.

26. Shaw AC, Goldstein DR, Montgomery RR. Age-dependent dysregulation of innate immunity. Nat Rev Immunol 2013; 13 (12):875.

27. Xu Z, Shi L, Wang Y, et al. Pathological findings of COVID-19 associated with acute respiratory distress syndrome. Lancet Respir Med 2020; 8(4):420.

28. Feng Z, Diao B, Wang R, et al. The novel severe acute respiratory syndrome coronavirus 2 (SARS-CoV-2) directly decimates human spleens and lymph nodes. MedRxiv 2020.03.27.20045427; doi: https://doi.org/10.1101/2020.03.27.20045427
29. Gruver AL, Hudson LL, Sempowski GD. Immunosenescence of ageing. J Pathol 2007; 211(2):144.

30. Tanaka S, Inoue S, Isoda F, et al. Impaired immunity in obesity: suppressed but reversible lymphocyte responsiveness. Int J Obes Relat Metab Disord 1993; 17(11):631.

31. Yang H, Youm YH, Vandanmagsar B, et al. Obesity accelerates thymic aging. Blood 2009; 114(18):3803.

32. van der Weerd K, Dik WA, Schrijver B, et al. Morbidly obese human subjects have increased peripheral blood CD4+ T cells with skewing toward a Treg- and Th2-dominated phenotype. Diabetes 2012; 61(2):401.

33. Sierra-Filardi E, Nieto C, Dominguez-Soto A, et al. CCL2 shapes macrophage polarization by GM-CSF and M-CSF: identification of CCL2/CCR2-dependent gene expression profile. J Immunol 2014; 192(8):3858.

34. Liao M, Liu Y, Yuan J, et al. Single-cell landscape of bronchoalveolar immune cells in patients with COVID-19. Nat Med 2020; 26(6):842-4.

35. Hadjadj J, Yatim N, Barnabei L, et al. Impaired type I interferon activity and exacerbated inflammatory responses in severe Covid-19 patients. MedRxiv 2020; 369(6504):718-24.

36. Bastard P, Rosen LB, Zhang Q, et al. Auto-antibodies against type I IFNs in patients with life-threatening COVID-19. Science 2020; 370(6515):eabd4585.

37. Zhang C, Wu Z, Li JW, Zhao H, Wang GQ. Cytokine release syndrome in severe COVID-19: interleukin-6 receptor antagonist tocilizumab may be the key to reduce mortality. Int $J$ Antimicrob Agents 2020; 55(5):105954.

38. Sterner RM, Sakemura R, Cox MJ, et al. GM-CSF inhibition reduces cytokine release syndrome and neuroinflammation but enhances CAR-T cell function in xenografts. Blood 2019; 133 (7):697.

39. Miao M, De Clercq E, Li G. Clinical significance of chemokine receptor antagonists. Expert Opin Drug Metab Toxicol 2020; 16 (1):11.

40. Sportes C, Hakim FT, Memon SA, et al. Administration of rhIL-7 in humans increases in vivo TCR repertoire diversity by preferential expansion of naive T cell subsets. J Exp Med 2008; 205(7):1701.

41. Rosenberg SA, Sportes C, Ahmadzadeh M, et al. IL-7 administration to humans leads to expansion of CD8+ and CD4+ cells but a relative decrease of CD4+ T-regulatory cells. $J$ Immunother 2006; 29(3):313. 